\title{
Increasing the operational reliability of tractors by backing up the replacement elements
}

\author{
Mihail Buraev ${ }^{1, *}$, Galina Buraeva ${ }^{1}$, Vladimir Belomestnykh ${ }^{1}$, Tsedashi Tsedashiev $^{1}$, and \\ Sergey Altukhov ${ }^{1}$ \\ ${ }^{1}$ Irkutsk state agricultural university named after A. A. Ezhevsky, 664038, Irkutsk region, Irkutsk \\ district, Molodezhny, Russian Federation
}

\begin{abstract}
The article deals with the issues of choosing a redundancy method and the frequency of replacing tractor elements while ensuring the level of operational reliability in agricultural enterprises. It is noted that the operability of the system is ensured as long as there are reserve elements available to replace the failed main elements (and there is a possibility of switching the reserve elements into an operational state). One of the general methods for solving this problem is a method based on the use of Markov processes. In this case, the process of changing the states of the tractor is presented as a dynamic system, the state of which changes discretely in continuous time in a random manner.
\end{abstract}

\section{Introduction}

In the process of their intended use, tractors and their elements under the influence of external and internal factors lose their efficiency and consumer qualities [1-5]. To achieve a high level of operational reliability of tractors at the places of use, technological and organizational measures are necessary to ensure prompt and high-quality elimination of failures and malfunctions [6-9].

When establishing the place and nature of the refusal, two situations are possible. In the first case, the faulty component is identified, and the required amount of dismantling work depends on its availability. In the second case, only a faulty unit, a mechanism or a group of components are identified, including a faulty one. It is possible to find and give an opinion on it only after partial disassembly. In both cases, the restoration of the machine's performance is carried out by replacing individual faulty or worn out units and assemblies with repaired or new ones from the number of spare parts or the stock of exchange units $[1,10$ 15]. Here, the tractor's adaptability to carry out the specified types of work, as well as to work on refueling, preparation for use, storage and other operations performed during tractor operation, comes to the fore $[2,8]$.

The most typical maintenance tasks are performed when replacing non-recoverable elements - air and fuel filters, technical fluids at the end of the established resource. As a rule, these types of consumables are always in the field of view of service departments. The situation is different with the elements, the demand for replacement of which arises as a

\footnotetext{
Corresponding author : buraev@mail.ru
} 
result of failures and malfunctions during the operation of machines [6, 8].

Analysis of tractor failures and malfunctions showed that such reliability indicators as mean time between failures, failure flow parameter and specific total duration of unscheduled repairs are relatively low. For example, according to [1], the probability of failure of the CLAAS tractors was estimated at 0.225 , and the failure flow parameter was 0.0036 . Sudden failures of the running system, engine and hydraulic equipment in total accounted for $19 \%$ of the total number of failures, and total and resource failures are 19 and 3\%, respectively; failures in the hydraulic system are predominant $(43.2 \%)$.

When the tractors are restored to work, the absence of a spare element on site and at the dealer's warehouses necessitates a request for it from the manufacturer. As a result, downtime and repair costs increase significantly [12]. In these conditions, it is advisable to use redundancy [9].

\section{Purpose of the study}

Justify the ways of redundancy during the technical inspection and repair of tractors.

\section{Research methodology}

The initial information for substantiating the methods of reserving the repair resources of elements during the technical inspection and repair of tractors was data on the production and technical operation of tractors - logs of registration of failures and operating time of machines, operational and intermediate reports of service managers of Agroresource LLC, service documentation on carrying out repair and maintenance operations, schedules of PPR and technical inspection of machines, defect lists [2]. The sampling, in addition to data on the first replacements of parts, contained information about the number of replaced parts, their location, the serial number of the replacement and its brief reason. The minimum sample size was set depending on the type and functional purpose of parts using the provisions of GOST 27.502-83.

Various methods of redundancy developed in the theory of reliability pursue one main goal - the creation of reliable systems from unreliable elements $[1,9]$. The system operability is ensured as long as reserve elements are available to replace the failed main elements (and there is a possibility of switching the reserve elements into an operational state). One of the general methods for solving this problem is the method based on the use of Markov processes $[3,4]$.

We represent the process of changing the tractor states as a dynamic system, the state of which changes discretely in continuous time in a random manner. All elements of this system are constantly moving from one quality to another. $\left(S^{l} \rightarrow S^{2}\right)$ and as a result of failure (state $S^{3}, S^{4}$ ) require restoration of working capacity (figure 1). Information about downtime due to lack of reserves can be considered as a complete group of states [4]:

- period of normal use of machines for their intended purpose $-t_{p}$;

- period of downtime for maintenance and elimination of technical and technological failures resulting in poor quality of work and a decrease in intensity $-t_{v}$;

-period of MTA downtime for organizational reasons $-t_{p r}$;

- uncertainty of information received from the system is defined as entropy. 


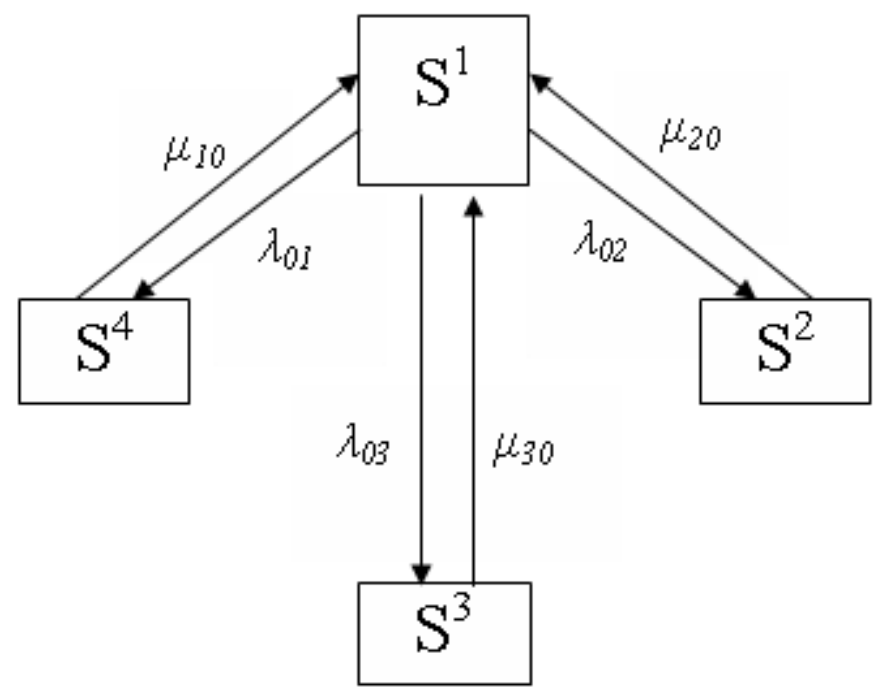

Fig. 1. Graph of conditional tractor states

On the state graph $\lambda, \mu$ - streams of events that transfer the tractor from an operable state to an inoperative state and vice versa.

The system of differential equations for average number of tractors is written as follows:

$$
\left\{\begin{array}{l}
\frac{d N_{0}^{\prime}(t)}{d t}=-l_{c}\left[\lambda_{01}(t)+\lambda_{02}(t)+\lambda_{03}(t)\right] \cdot N_{0}^{\prime}(t)+\mu_{10}(t) \cdot N_{1}(t)+ \\
+\mu_{20}(t) \cdot N_{2}(t)+\mu_{30}(t) \cdot N_{3}(t) \\
\frac{d N_{1}(t)}{d t}=-\mu_{10}(t) \cdot N_{1}(t)+l_{c} \cdot N_{0}^{\prime}(t) \cdot \lambda_{01}(l) \\
\frac{d N_{2}(t)}{d t}=-\mu_{20}(t) \cdot N_{2}(t)+l_{c} \cdot N_{0}^{\prime}(t) \cdot \lambda_{02}(t) \\
\frac{d N_{3}(t)}{d t}=-\mu_{30}(t) \cdot N_{3}(t)+l_{c} \cdot N_{0}^{\prime}(l) \cdot \lambda_{03}(t)
\end{array}\right.
$$

According to the mnemonic rule [1], we put the left sides of the equations equal to zero, we obtain a system of algebraic equations for the average numbers of machines operating in a stationary mode:

$$
\left\{\begin{array}{l}
0=-l_{c}\left(\lambda_{01}+\lambda_{02}+\lambda_{03}\right) \cdot N_{0}^{\prime}+\mu_{10} N_{1}+\mu_{20} N_{2}+\mu_{30} N_{3} \\
0=-\mu_{10} N_{1}+l_{c} \lambda_{01} N_{0}^{\prime} \\
0=-\mu_{20} N_{2}+l_{c} \lambda_{02} N_{0}^{\prime} \\
0=-\mu_{30} N_{3}+l_{c} \lambda_{03} N_{0}^{\prime}
\end{array}\right.
$$

Let us solve the system of algebraic equations taking into account the so-called normalization condition:

$$
N=N_{0}^{\prime}+N_{2}+N_{3}+N_{4},
$$

where $N$ - average number of tractors, units. 
From system (2) we determine the unknown mean numbers of states, using $N_{0}^{\prime}$. So, from the second and third equations we have:

$$
\begin{aligned}
& N_{1}=l_{c} \frac{\lambda_{01}}{\mu_{10}} N_{0}^{\prime} . \\
& N_{2}=l_{c} \frac{\lambda_{02}}{\mu_{20}} N_{0}^{\prime} .
\end{aligned}
$$

According to the normalization condition

$$
N_{3}=N_{0}-N_{0}^{\prime}-N_{l}-N_{2}
$$

Then

$$
\begin{aligned}
& N_{3}=N_{0}-\left[N^{\prime}{ }_{0}+N^{\prime}{ }_{0} l_{c} \frac{\lambda_{01}}{\mu_{10}}+N^{\prime}{ }_{0} l_{c} \frac{\lambda_{02}}{\mu_{20}}\right]= \\
& =N_{0}-\left[1+l_{c} \frac{\lambda_{01}}{\mu_{10}}+l_{c} \frac{\lambda_{02}}{\mu_{20}}\right] N^{\prime}{ }_{0} .
\end{aligned}
$$

Substituting (7) into equation (2), we obtain:

$$
\begin{aligned}
& 0=-l_{c}\left(\lambda_{01}+\lambda_{02}+\lambda_{03}\right) N_{0}^{\prime}+l_{c} \lambda_{01} N_{0}^{\prime}+l_{c} \lambda_{02} N_{0}^{\prime}+\mu_{30}\left[N_{0}-\left(1+l_{c} \frac{\lambda_{01}}{\mu_{10}}+\right.\right. \\
& \left.\left.+l_{c} \frac{\lambda_{02}}{\mu_{20}}\right) N_{0}^{\prime}\right]=-l_{c} \lambda_{03} N_{0}^{\prime}+\mu_{30} N_{0}-\mu_{30}\left(1+l_{c} \frac{\lambda_{01}}{\mu_{10}}+l_{c} \frac{\lambda_{02}}{\mu_{20}}\right) N_{0}^{\prime} .
\end{aligned}
$$

Divide the resulting equation by $\mu_{30}$ :

$$
-l_{c} \frac{\lambda_{03}}{\mu_{30}} N_{0}^{\prime}+N_{0}^{\prime}+N_{0}-\left[1+l_{c} \frac{\lambda_{01}}{\mu_{10}}+l_{c} \frac{\lambda_{02}}{\mu_{20}}\right] N_{0}^{\prime}=0 .
$$

The last equation can be written as follows:

$$
N_{0}=\left[1+l_{c} \frac{\lambda_{01}}{\mu_{10}}+l_{c} \frac{\lambda_{02}}{\mu_{20}}+l_{c} \frac{\lambda_{03}}{\mu_{30}}\right] N_{0}^{\prime} .
$$

Then the availability of machines in the system of industrial and technical operation will be equal to:

$$
K_{g}^{i t o}=\frac{N_{0} 0}{N_{0}}=\frac{1}{1+l_{c}\left(\frac{\lambda_{01}}{\mu_{10}}+\frac{\lambda_{02}}{\mu_{20}}+\frac{\lambda_{03}}{\mu_{30}}\right)},
$$

To achieve a high level of availability, it is necessary to improve the potential for repairing machines, when not only machine failures are eliminated, but also the ability to increase operating time to the limiting state is achieved, which increases the efficiency of tractors through a reasonable choice of operational redundancy. The multiplicity of redundancy $\mathrm{m}$ required to achieve a given level of reliability (availability) of a redundant object at a certain point in time for a given reliability of the main object can be found from the expression [9]: 


$$
m=\frac{\ln \left[1-K_{3}(t)\right]}{\ln \left[1-K_{o}(t)\right]}-1=\frac{\ln Q_{3}(t)}{\ln Q_{o}(t)}-1,
$$

where $K_{3}(t)$ - the given availability factor (reliability) of a redundant object at a certain point in time;

$K_{o}(t)$ - availability ratio (reliability) of the main facility without redundancy.

The reasons for the failures of the mechanical part of the tractors were of a different nature, failures and malfunctions manifested themselves differently [13]. From table 1 it follows that the main part of failures and malfunctions of tractors arose due to the tough operation of tractors, as well as due to the human factor [14]. Mechanical parts account for $55.2 \%$ of the total number of failures and $68.5 \%$ of the total loss of time.

Table 1. Main failures and malfunctions of tractors (fragment)

\begin{tabular}{|c|c|c|c|c|}
\hline $\begin{array}{l}\text { Tractor } \\
\text { brand }\end{array}$ & Fault & Fault description & Fault photo (cause) & Fault solution \\
\hline $\begin{array}{c}\text { Wheel } \\
\text { tractor ATLES } \\
946 \mathrm{RZ}\end{array}$ & $\begin{array}{l}\text { Front axle } \\
\text { differential }\end{array}$ & $\begin{array}{l}\text { Destruction of the bearing } \\
\text { of the bevel gear shaft of the } \\
\text { driving front axle, which in } \\
\text { turn led to destruction of the } \\
\text { bevel pair, main gears and } \\
\text { satellites and their axles, and } \\
\text { the differential housing. Possi- } \\
\text { ble cause is insufficient trans- } \\
\text { mission oil in the front drive } \\
\text { axle housing. }\end{array}$ & & $\begin{array}{l}\text { Replacement } \\
\text { of bearing, conic } \\
\text { pair, satellites, } \\
\text { satellite axles. } \\
\text { Repair of the } \\
\text { bearing seat. }\end{array}$ \\
\hline $\begin{array}{c}\text { Wheel } \\
\text { tractor ATLES } \\
946 \mathrm{RZ}\end{array}$ & Generator & \begin{tabular}{l}
\multicolumn{1}{c|}{ Battery emergency lamp } \\
was dimly lit on the panel and \\
the engine speed was not indi- \\
cated on the tachometer when \\
the engine was started. In the \\
course of diagnostics of the \\
electrical equipment, it was \\
revealed that the generator was \\
faulty, there was a weak solder- \\
ing of one wire from the stator \\
winding to the diode bridge. \\
\end{tabular} & & $\begin{array}{l}\text { Replacing the } \\
\text { diode bridge of the } \\
\text { generator. }\end{array}$ \\
\hline $\begin{array}{c}\text { Wheel } \\
\text { tractor } \\
\text { AXION } 850\end{array}$ & $\begin{array}{l}\text { Variable } \\
\text { gear box }\end{array}$ & $\begin{array}{l}\text { The tractor does not move } \\
\text { forward, only backward. The } \\
\text { reason is the failure of the } \\
\text { "Revershift" control solenoid } \\
\text { valve. }\end{array}$ & & $\begin{array}{l}\text { Replacing the } \\
\text { solenoid valve }\end{array}$ \\
\hline
\end{tabular}

To replace the failed elements of the tractors, a pre-prepared fund (stock) of replaceable repair elements was used, that is, redundancy of spare parts and parts was ensured. In this case, unloaded redundancy was implemented, which leads to the complication and rise in the cost of repairs, but this increases the reliability of the tractors [15]. 
Table 2. Significance of replacement of tractor elements

\begin{tabular}{|c|c|c|c|}
\hline $\begin{array}{c}\text { Factors characterizing the } \\
\text { consequences of failures }\end{array}$ & $\begin{array}{c}\text { Multiplicity of re- } \\
\text { placements, } m\end{array}$ & $\begin{array}{c}\text { Number of re- } \\
\text { serve objects }\end{array}$ & $\begin{array}{c}\text { Number of main } \\
\text { objects }\end{array}$ \\
\hline $\begin{array}{c}\text { Costs of eliminating the con- } \\
\text { sequences of failures }\end{array}$ & 1 & 1 & 1 \\
\hline $\begin{array}{c}\text { Losses from machine } \\
\text { downtime }\end{array}$ & 2 & 2 & 1 \\
\hline $\begin{array}{c}\text { The complexity of eliminating } \\
\text { the consequences of failure (re- } \\
\text { quirements for the repair base) }\end{array}$ & 3 & 3 & \\
\hline
\end{tabular}

For machines with integer redundancy factor $m=1$, one main and one reserve element were reserved, and the total number of tractor reserve elements was two. If $m=3$, the reservation is made with an integer multiple. This means that you need to have one main and three spare elements in stock, and the total number of elements is four. If $m=2$ this will mean redundancy with integer multiplicity, in which the number of reserve elements is 2 , and the total number of elements is 3 . If $m=4 / 2$, this means the presence of redundancy with fractional multiplicity, in which the number of reserve elements is is 4 , the number of main elements is 2 , and the total number of elements is 6 .

If the number of primary and backup elements is equal, the unloaded reserve provides higher system reliability than the loaded one. But at the same time, difficulties arise with the organization and technological processes of replacing elements, associated with the cost of labor and material resources. Therefore, the transfer of the reserve element to the working condition must be carried out taking into account these factors and absolutely reliably.

\section{Conclusion}

Operational redundancy allows you to quickly eliminate failures and malfunctions of tractors, including the mechanical part, which accounts for $55.2 \%$ of the total number of failures and $68.5 \%$ of the total loss of time. Redundancy makes it possible to provide the set level of the availability factor and the likelihood of no-failure of tractors in the next overhaul period, increasing the level of operational reliability of tractors.

\section{References}

1. Database of LLC "Agroresurs", Ulan-Ude - Shelekhov, 150 (2013 - 2018)

2. E. V. Eltoshkina, M. K. Buraev, T. V. Bodyakina, Ensuring the operability and fault tolerance of machines by reserving replaceable elements, Tractors and agricultural machines, 6, 54-58 (2019)

3. Ye. A. Puchin, Evaluation of the reliability of serial domestic (CIS) and foreign tractors, Bulletin of NGIEI, 2(3), 173 - 178 (2011)

4. A. V. Shisteev, Improving the repair manufacturability of agricultural tractors by using replaceable-exchange elements, Materials of the international scientific and practical conference "Environmental safety and prospects for the development of agricultural production in Eurasia ", 3-4 December 2013, 13-115 Irkutsk: Publishing house IRGSHA (2013)

5. M. Buraev, To clarify the standards of spare parts for technical service of autotractors in zone conditions, E3S Web of Conferences. XIII International Scientific and Practical Conference "State and Prospects for the Development of Agribusiness INTERAGROMASH 2020”, 05001 (2020) 
6. T. Bodyakina, Diagnostics of hydraulic density of plunger couple of tractor diesel, E3S Web of Conferences. XIII International Scientific and Practical Conference "State and Prospects for the Development of Agribusiness - INTERAGROMASH 2020”, 05035 (2020)

7. Ya. Ivanyo, Management models of agrarian production in the conditions of high risks. Critical Infrastructures in the Digital World (IWCI-2020). Proceeding of International Workshop (2020)

8. N. I. Ovchinnikova, Simulation diagnostics of power train mechanical drives. III International Scientific Conference: AGRITECH-III-2020: Agribusiness, Environmental Engineering and Biotechnologies. Krasnoyarsk Science and Technology City Hall of the Russian Union of Scientific and Engineering Associations, 52033 Krasnoyarsk, Russia (2020)

9. N. I. Ovchinnikova, A simple semi-markov model of functioning of agricultural cleaning and transport system, Journal of Physics: Conference Series. The proceedings International Conference "Information Technologies in Business and Industry", 032061 (2019)

10. E. V. Eltoshkina, Evaluation of the limit properties of a solid body system, IOP conference series: MATERIALS SCIENCE AND ENGINEERING. Irkutsk National Research Technical University, 012023 (2019)

11. N. V. Chubareva, Resource-saving by choosing methods of tractors maintenance, IOP Conference Series: Materials Science and Engineering, 632(1), 012045 (2019)

12. S. V. Agafonov, Lecture notes in electrical engineering, 1 November, 307, 279-292, (2014)

13. V. I. Karagodin, Rationale and frequency of the diagnosis of component parts of tractors Belarus in the development of technology maintenance, IOP Conference Series: Materials Science and Engineering, 832(1), 012005 (2020)

14. E. L. Lipkovich, Agricultural tractors of the fth generation, Scientia Iranica 27(2B), 745-756 (2020)

15. I. Galiev, Ensuring possibility of functioning of tractors in agricultural production taking into account residual resources of their units and systems, Engineering for Rural Development, 48-53 (2020) 